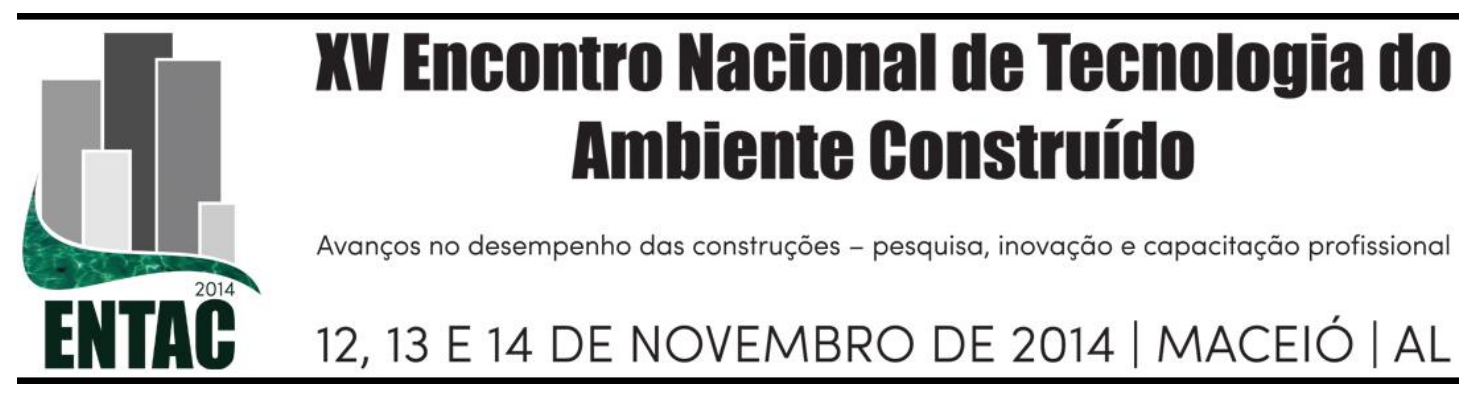

\title{
PRINCÍPIOS ENXUTOS NA GESTÃO DO PROCESSO DE PROJETO: ESTUDO DE CASO EM UMA CONSTRUTORA
}

\author{
FRANCO, Jéssica V. (1); PICCHI, Flávio A. (2); MELHADO, Silvio B. (3) \\ (1) Universidade Estadual de Campinas, e-mail: j.valejofranco@gmail.com \\ (2) Universidade Estadual de Campinas, e-mail: fpicchi@lean.org.br, \\ (3) Universidade de São Paulo, e-mail: silviobmelhado@gmail.com
}

\begin{abstract}
RESUMO
A mentalidade enxuta é aplicada ao desenvolvimento de produto na indústria automobilística há algumas décadas, no entanto, no setor da Construção verificam-se poucas pesquisas que tratam o tema, em especial em empreendimentos brasileiros. Sendo assim, este trabalho tem como objetivo avaliar o grau de adesão aos princípios enxutos na gestão do processo de projeto de um Empreendimento em uma empresa Construtora. Parte-se da hipótese que mesmo as empresas que não utilizam o processo enxuto de forma declarada já aplicam alguns princípios na gestão de seus projetos. A estratégia de pesquisa contemplou primeiramente revisão bibliográfica sobre o tema na qual foram extraídos princípios enxutos aplicáveis à gestão de projetos que serviram de base para a segunda etapa da pesquisa: análise de um estudo de caso em uma empresa Construtora. Os resultados do estudo apontaram que o único princípio com total adesão aos conceitos de gestão enxuta de projetos foi referente à utilização de uma equipe de especialistas. Alguns princípios apresentaram adesão apenas parcial e ao avaliar a liderança do processo de projeto foi verificado que não havia nenhuma adesão aos princípios enxutos. Esse artigo pode contribuir com trabalhos futuros que queiram identificar os possíveis caminhos para a aplicação total da gestão enxuta no processo de projeto em empreendimentos da Construção.
\end{abstract}

Palavras-chave: gestão enxuta do processo de projeto, gestão do processo de projeto, mentalidade enxuta

\begin{abstract}
Lean thinking has been applied for some decades on Product Development in the Auto Industry; however, in the Construction sector few researches have approached this theme, especially in Brazilian Projects. This paper aims at evaluating a Project's design management process in terms of the degree of adherence to lean principles. It was started from the hypothesis that, even companies that don't openly declare to apply a lean process, in fact already use some principles in their design management process. The research strategy began with a literature review from where the lean principles were extracted and used as the base for the second phase of the research: a case study in a Construction company. The results showed that the only principle that had full adherence was the one in regard to the Specialist Team. Some principles had only partial adherence and, while evaluating the leadership in the design process, it was observed that it had none adherence to lean principles. This paper can contribute with future researches that may aim at identifying ways for full application of lean design management in Construction projects.
\end{abstract}

Keywords: lean design management, design management, lean thinking

\section{INTRODUÇÃO}

A mentalidade enxuta é aplicada ao desenvolvimento de produto na indústria automobilística há algumas décadas, no entanto, no setor de Construção Civil verificamse poucas pesquisas que tratam o tema, em especial em empreendimentos brasileiros. 
Dal Forno e Forcellini (2012) fizeram um levantamento de publicações que tratavam temas relacionados ao processo enxuto de desenvolvimento de produtos e dentre 247 publicações analisadas somente 8 eram do setor de Construção, o que mostra a lacuna de conhecimento nesta área e a justificativa para esta pesquisa.

Sendo assim, este trabalho tem como objetivo avaliar a gestão do processo de projeto de um empreendimento em uma empresa construtora quanto ao grau de adesão aos princípios enxutos.

Parte-se da hipótese que mesmo as empresas que não utilizam de forma declarada um processo enxuto já aplicam alguns princípios na gestão de seus projetos. A contribuição deste artigo pode auxiliar em trabalhos futuros que queiram identificar os possíveis caminhos para o desenvolvimento de um método de aplicação dos conceitos enxutos voltado à gestão do processo de projeto.

\section{PRINCÍPIOS ENXUTOS NA GESTÃO DO PROCESSO DE PROJETO}

Ao falar sobre a aplicação de conceitos enxutos na gestão de projetos, é necessário primeiramente abordar os autores que tratam sua aplicação ao desenvolvimento de produtos, sem que haja ligação direta com o setor da Construção. Womak et. al. (2004) relatou toda a história da Toyota e de como a mentalidade enxuta revolucionou a indústria automobilística sempre com foco na redução de desperdício e no aumento de valor. Junto a isso, os autores também apresentaram como esses conceitos influenciaram no desenvolvimento de produto e foram listadas algumas técnicas que contribuíram para o sucesso de seus Projetos, sendo elas:

- Liderança (engenheiro-chefe)

- Trabalho integrado em equipe

- Comunicação

- Engenharia Simultânea

Apesar de algumas técnicas abordando o desenvolvimento de projeto já terem sido discutidas anteriormente, o chão de fábrica sempre foi o ponto de partida da implementação da mentalidade enxuta. De acordo com Morgan e Liker (2008), o desenvolvimento de produtos e processos pode ter um impacto maior sobre a empresa enxuta do que a produção enxuta. Desta forma, a partir de um extenso estudo sobre o sistema Toyota de desenvolvimento de produtos, os autores elaboraram treze princípios categorizados em processos, pessoal e ferramentas que trilham os caminhos para aplicação de um sistema enxuto de desenvolvimento de produto, estes princípios estão resumidos na Figura 01.

Ward et. al (2011) mostrou de forma detalhada os principais conceitos enxutos que podem ser incorporados à gestão de projetos, além de descrever ferramentas e processos que podem favorecer essa aplicação. 


\section{Figura 1: Os 13 princípios do Sistema Toyota de Desenvolvimento de Produtos}

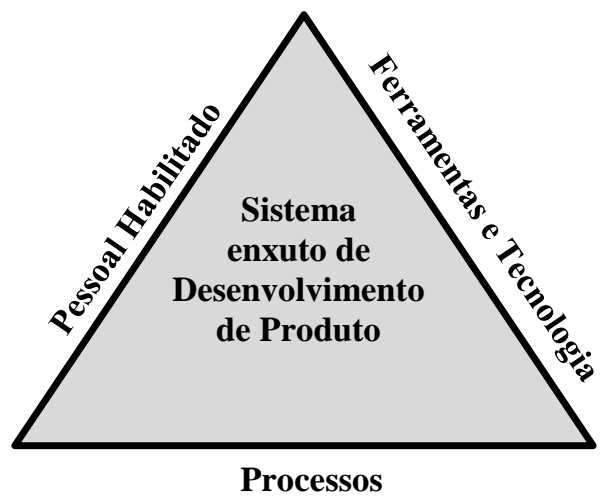

\section{PROCESSOS}

1 Identifique valor definido pelo cliente para separar valor agregado do desperdício

2 Concentre esforços no início do processo de DP para explorar as alternativas

3 Crie um nivelamento de fluxo do processo de DP

4 Utilize padronização rigorosa para reduzir a variação e criar flexibilidade e resultados previsíveis

\section{PESSOAS}

5 Desenvolva um sistema de engenheiro chefe para liderar o desenvolvimento do início ao fim

6 Organize para balancear a competência funcional com a integração multifuncional

7 Desenvolva a competência técnica superior em todos os engenheiros

8 Integre plenamente os fornecedores ao sistema de DP

9 Consolide o aprendizado e a melhoria contínua

10 Construa uma cultura de suporte à excelência e à melhoria ininterrupta

11 Adapte a tecnologia ao pessoal e ao processo

FERRAMENTAS

12 Alinhe e organize mediante comunicação simples e visual

13 Use ferramentas poderosas para padronização e o aprendizado organizacional

Fonte: Adaptado de Morgan e Liker (2008)

A Tabela 1 mostra os conceitos de Ward et. Al. (2011) e a descrição resumida de cada um deles. Por se tratar de uma referência atual e pelo fato de abordar os principais conceitos enxutos sobre o tema, esses princípios foram utilizados como base para o comparativo do estudo de caso realizado neste trabalho.

Tabela 1: Princípios enxutos para o desenvolvimento de produtos e processos.

\begin{tabular}{|l|l|l|}
\hline $\mathbf{N}^{0}$ & Princípio & Descrição resumida \\
\hline 1 & $\begin{array}{l}\text { Foco no valor: conhecimento e } \\
\text { fluxo de valor operacional }\end{array}$ & $\begin{array}{l}\text { O desenvolvimento enxuto defende que toda cadeia produtiva } \\
\text { deve estar focada na criação de valor, ou seja, fornecedores, } \\
\text { desenvolvedores e operação precisam buscar a melhoria do } \\
\text { produto em todos aspectos: de produção, de atributos } \\
\text { entregues, de custo, de qualidade, etc. É importante que todas } \\
\text { essas características estejam alinhadas entre si havendo um } \\
\text { balanceamento para que algumas partes não sejam otimizadas } \\
\text { sacrificando outras. A função dessa cadeia de valor também é } \\
\text { de gerar conhecimento reutilizável pela empresa, que possa ser } \\
\text { aplicado em outros projetos. }\end{array}$ \\
\hline 2 & $\begin{array}{l}\text { É o líder do projeto (engenheiro chefe) que representa o cliente, } \\
\text { traz rentabilidade, guia acordos e trade-offs, gera o } \\
\text { desenvolvimento, provê a visão, projeta o sistema do fluxo de } \\
\text { empreendedor }\end{array}$ \\
\hline
\end{tabular}




\begin{tabular}{|l|l|l|}
3 & $\begin{array}{l}\text { Engenharia simultânea com } \\
\text { múltiplas alternativas }\end{array}$ & $\begin{array}{l}\text { Explora simultaneamente soluções múltiplas para cada } \\
\text { subsistema. Ataca arrojadamente essas soluções com análises e } \\
\text { testes rápidos e de baixo custo, progressivamente eliminando } \\
\text { soluções fracas. Utiliza os resultados das análises e testes para } \\
\text { criar uma base de conhecimento de curvas de trade-off que } \\
\text { define os limites do possível. Converge em uma solução apenas } \\
\text { depois que foi comprovado. }\end{array}$ \\
\hline 4 & $\begin{array}{l}\text { Cadência, fluxo e puxada } \\
\text { utilizar eventos meta para puxar o desenvolvimento dos } \\
\text { projetos enquanto se estabelece um ritmo cíclico para as } \\
\text { atividades de desenvolvimento de forma que as pessoas sempre } \\
\text { saibam o que precisam fazer e mantenham um fluxo de } \\
\text { trabalho contínuo no qual todas as informações e recursos } \\
\text { necessários sempre estão disponíveis ao longo do processo. }\end{array}$ \\
\hline 5 & $\begin{array}{l}\text { Equipes de especialistas } \\
\text { responsáveis }\end{array}$ & $\begin{array}{l}\text { São equipes de pessoas altamente especializadas em assuntos } \\
\text { distintos e que são capazes de projetar seu próprio trabalho. } \\
\text { Essas equipes aprendem com conflitos e são capazes e criar e } \\
\text { utilizar novo conhecimento nos projetos. }\end{array}$ \\
\hline
\end{tabular}

Fonte: Adaptado de Ward et. Al. (2011).

A aplicação dos princípios enxutos na Construção começou a ser discutida considerando as etapas produtivas de obra e junto a isso, surgiu a necessidade de também estudar sua utilização na etapa de projetos. Ballard e Zabelle (2000) apresentaram a mentalidade enxuta no desenvolvimento de projetos da Construção colocando as etapas para a estruturação de um Projeto bem como as técnicas e ferramentas necessárias para sua correta abordagem. Os itens propostos pelos autores foram adaptados de soluções similares utilizadas pela indústria de manufatura, conforme mostrado abaixo:

- Estruturar o projeto com equipes multidisciplinares

- Buscar a pratica da engenharia simultânea

- Estruturar o trabalho baseado nos ideais da filosofia enxuta

- Minimizar interações negativas

- Utilizar o sistema Last Planner para controle da produção do Projeto

- Utilizar tecnologias que facilitem a aplicação dos princípios enxutos ao desenvolvimento de projetos

As etapas acima estão todas diretamente relacionadas tanto com as técnicas apresentadas por Womak et. Al. (2004) quanto pelos princípios trazidos posteriormente por Ward et. Al. (2011). No entanto, é importante destacar que na publicação de Ballard e Zabelle(2000) não foi citada a figura do líder ou engenheiro-chefe, atribuindo a aplicação dos princípios enxutos apenas à gestão do processo e não à características da equipe que o gerencia.

Em estudos mais recentes, Reifi e Emmitt (2013) também destacaram os principais temas relacionados ao processo enxuto de desenvolvimento de projetos encontrados na literatura. São eles:

- Definição do programa de necessidades do projeto e interação com o cliente

- Valor e mapeamento do fluxo de valor

- Cultura enxuta e estruturação da equipe

- Fluxo de informações 
Da mesma forma, os temas acima também estão relacionados com a literatura conceitual do tema, com exceção do primeiro tema em que já se fala de programa de necessidades e interação com o cliente, itens bem particulares de projetos da Construção, o que mostra um avanço no conhecimento sobre o tema aplicado a Edificações.

No entanto, apesar do avanço de conhecimento publicado sobre o tema, considera-se que sua aplicação na prática ainda não está consolidada no mercado de Construção. Na pesquisa de Reife e Emmitt (2013) foram realizadas entrevistas com 125 profissionais do setor de Construção do Reino Unido e seus resultados mostraram que quase três quartos dos entrevistados não tinham em seus processos nenhuma técnica que favorecesse a redução de desperdícios e o aumento de valor para seus clientes e apenas $15 \%$ dos entrevistados declararam utilizar abordagem enxuta para seus projetos. Esse panorama apresentado pelos autores mostra a necessidade de continuação das pesquisas no setor em busca de obter dados para identificar caminhos para a aplicação da mentalidade enxuta em projetos de Edificações.

\section{MÉTODOS}

O método de pesquisa deste trabalho contempla as seguintes etapas:

a) Revisão bibliográfica do tema

b) Seleção dos princípios enxutos aplicáveis ao processo de projeto

c) Caracterização do caso estudado

d) Análise documental do estudo de caso

e) Análise do estudo de caso em relação à adesão aos princípios enxutos

f) Conclusões

Primeiramente, foi realizada uma revisão da bibliografia do tema em busca de levantar os principais conceitos e definições atrelados à gestão enxuta de projetos. Á partir disso, foi extraído da literatura, princípios enxutos que serviram de base para a análise do estudo de caso.

Os princípios eleitos para o comparativo do estudo de caso foram os descritos por Ward et. Al. (2011). Procurou-se utilizar uma referencia conceitual mais forte, mesmo que não seja diretamente voltada a projetos de construção, para que a análise do empreendimento seja baseada em conceitos e não em ferramentas ou em literatura gerada a partir da aplicação destes princípios em outras realidades, que não a brasileira.

O estudo de caso escolhido é um projeto do setor hoteleiro de alto luxo cujo processo de projeto estava sendo gerenciado por uma empresa construtora de São Paulo, na época da coleta de dados.

A análise foi feita baseada em dados documentais, sendo eles: contratos dos projetistas e da construtora, atas de reunião, cronogramas, relatórios de análise crítica, relatórios gerenciais e fichas de EAV (Engenharia e Análise de Valor). O intuito foi identificar o grau de adesão da gestão do projeto aos princípios enxutos para verificar se alguns destes princípios já estão sendo aplicados na empresa estudada, que não os praticam de forma declarada. 


\section{RESULTADOS}

\subsection{Caracterização do estudo de caso}

\section{A empresa construtora}

A empresa construtora estudada é de grande porte tendo cerca de 800 funcionários e 40 anos de existência. Tem sede na cidade de São Paulo e atua em obras em todo território nacional. Trabalha exclusivamente com projetos do setor privado com foco em empreendimentos comerciais, corporativos, hoteleiros bem como hospitais e shoppings.

A empresa tem como negócio principal a construção de edifícios e também trabalha com serviços de engenharia atuando em projetos na fase de Pré-Construção nos quais a gestão do processo de projeto, a orçamentação e o planejamento da obra ficam sob responsabilidade da empresa.

\section{O empreendimento}

O empreendimento estudado é um resort de luxo, padrão cinco estrelas projetado em um terreno no estado de Pernambuco. A área construída é de $33.000 \mathrm{~m}^{2}$ e o programa contempla: 160 quartos, 3 restaurantes, spa, fitness, piscinas e campo de golf.

O desenvolvimento da etapa de Pré-Construção teve início em outubro de 2012 na empresa Construtora e os dados para esta pesquisa foram coletados após um ano de desenvolvimento, em novembro de 2013.

O cliente da empresa Construtora é um grupo investidor brasileiro com intenção de investir na construção do empreendimento e participar nos lucros da operação por dez anos. O Operador é um grupo hoteleiro norte-americano. Na época em que os dados foram coletados o empreendimento estava na fase de projeto Identificação e Solução de Interfaces de Projeto (AGESC, 2012) ou Projeto Básico (NBR 13531,1995). As obras ainda não haviam sido iniciadas.

\section{A gestão do processo de projeto}

A empresa construtora foi contratada pelo cliente desde a fase de Concepção do Produto (AGESC, 2012) em um contrato que tinha como base o atingimento de um custo meta imposto pelo cliente.

A contratação dos projetistas principais (Arquitetura, Estrutura, Interiores, Paisagismo e Instalações) foi feita logo no início do processo. É importante ressaltar que o grupo hoteleiro impôs que somente projetistas e consultores homologados por eles poderiam ser contratados para o Projeto, o que fez com que todos os principais projetistas que atuam neste empreendimento fossem de origem estrangeira. O Cliente e a Construtora em busca de garantir que os projetos estivessem alinhados com as práticas locais, também contrataram projetistas nacionais para atuar em conjunto com os internacionais, tornando a gestão dos projetos e das informações mais complexa. A Tabela 03 mostra a lista dos projetistas e consultores contratados e suas nacionalidades.

A gestão do processo de projeto é escopo da Construtora dentro do contrato de PréConstrução, no entanto, foi dada ao arquiteto responsável pelo design a função de coordenar as disciplinas complementares, criando uma divisão das responsabilidades da gestão do processo de projeto conforme mostra a Figura 02.

Essa divisão de responsabilidades e outras características deste empreendimento fez com que o fluxo de gestão do processo não fosse linear ou concentrado em um só agente havendo partes do processo geridas por mais de um agente, como também é mostrado na Figura 02. As flechas que mostram a gestão indireta se referem ao fato de que, eventualmente, os agentes que não estavam oficialmente designados ao papel da 
gerenciar certo processo acabavam assumindo esta função ou solicitando ações e dando direcionamentos sem que isso fosse atribuído aos gestores principais.

\section{Tabela 2: Lista de projetistas e consultores do Empreendimento A, o escopo contratado e suas nacionalidades}

\begin{tabular}{|c|c|c|c|c|c|c|}
\hline \multirow{2}{*}{ Disciplina } & \multicolumn{4}{|c|}{ Fases (NBR 13531,1995) } & \multirow{2}{*}{ Escopo contratado } & \multirow{2}{*}{ Nacionalidade } \\
\hline & $\mathbf{E P}$ & $\mathbf{A P}$ & PB & $\mathbf{P E}$ & & \\
\hline Acústica & & & & & Consultoria em todas as fases & Canadá \\
\hline Acústica 2 & & & & & Projeto completo & Brasil \\
\hline Ar condicionado & & & & & Consultoria e projeto executivo & Brasil \\
\hline Arquitetura 1 & & & & & Projeto completo & EUA \\
\hline Arquitetura 2 & & & & & $\begin{array}{l}\text { Consultoria em todas as fases e } \\
\text { Projeto Legal }\end{array}$ & Brasil \\
\hline Automação 1 & & & & & Projeto até a fase pré-executivo & Inglaterra \\
\hline Automação 2 & & & & & Consultoria e projeto executivo & Brasil \\
\hline Bares e Restaurantes & & & & & Projeto completo & EUA \\
\hline Comunicação visual & & & & & Projeto completo & EUA \\
\hline Consultoria de elevadores & & & & & Projeto completo & EUA \\
\hline Consultoria de ferragens & & & & & Projeto completo & EUA \\
\hline Consultoria de spa & & & & & Consultoria em todas as fases & EUA \\
\hline Cozinha e lavanderia & & & & & Projeto completo & EUA \\
\hline Esquadrias/ fachada & & & & & Projeto completo & Inglaterra \\
\hline Estrutura & & & & & Projeto completo & Brasil \\
\hline Fundações & & & & & Projeto completo & Brasil \\
\hline Instalações 1 & & & & & Projeto até a fase pré-executivo & Canadá \\
\hline Instalações 2 & & & & & Consultoria e projeto executivo & Brasil \\
\hline Interiores & & & & & Projeto completo & EUA \\
\hline Luminotécnica 1 & & & & & Projeto até a fase pré-executivo & EUA \\
\hline Luminotécnica 2 & & & & & Consultoria e projeto executivo & Brasil \\
\hline Paisagismo & & & & & Projeto até a fase pré-executivo & EUA \\
\hline Paisagismo 2 & & & & & Consultoria e projeto executivo & Brasil \\
\hline $\begin{array}{l}\text { Terraplanagem/ } \\
\text { Pavimentação/ Drenagem }\end{array}$ & & & & & Projeto completo & Brasil \\
\hline
\end{tabular}

Fonte: Próprio autor.

\section{Figura 2: Fluxo de gestão do processo de projeto no Empreendimento - adaptado a partir de documentação disponibilizada pelo cliente}

\section{EMPREENDIMENTOA}

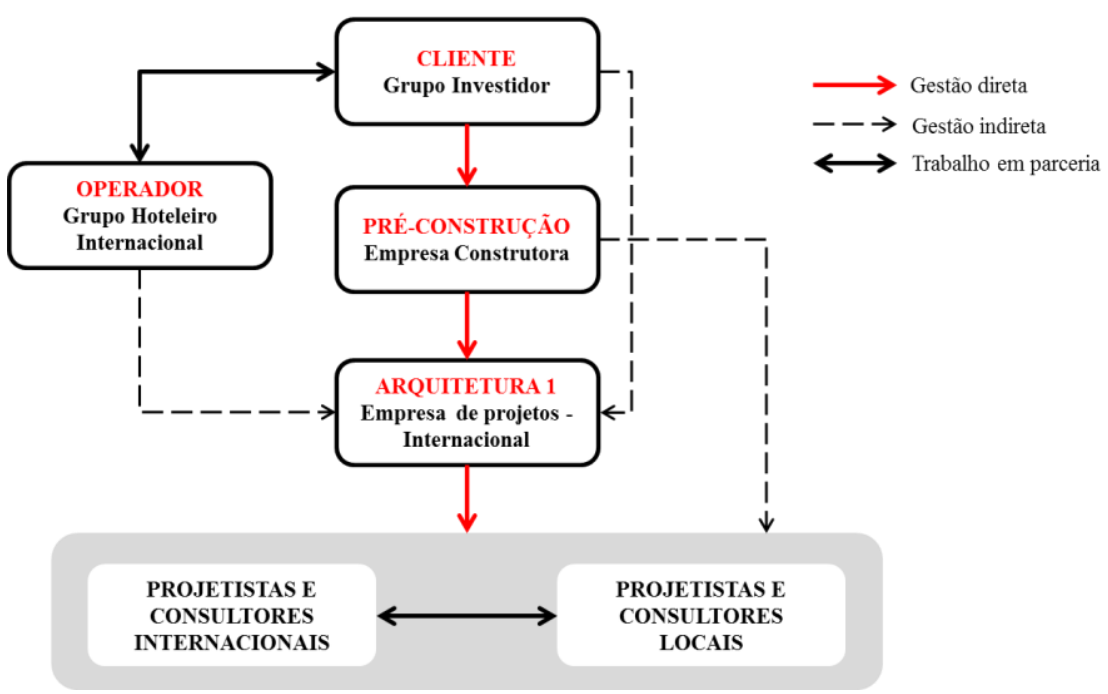

Fonte: Próprio autor. 


\subsection{Análise do grau de adesão aos princípios enxutos}

Para analisar o estudo de caso, foram utilizados como base os cinco princípios descritos por Ward et. al (2011) apresentados anteriormente na Tabela 01.

O resultado da análise está na Tabela 3 abaixo.

\section{Tabela 3: Análise do grau de adesão aos princípios enxutos em um empreendimento da Construção.}

\begin{tabular}{|c|c|c|c|}
\hline $\mathbf{N}^{0}$ & Princípio & $\begin{array}{c}\text { Adesão ao } \\
\text { princípio }\end{array}$ & Comentários \\
\hline 1 & $\begin{array}{l}\text { Foco no valor: conhecimento } \\
\text { e fluxo de valor operacional }\end{array}$ & Parcial & $\begin{array}{l}\text { Foram identificadas menções a estudos de } \\
\text { Engenharia de Valor nos relatórios gerenciais } \\
\text { analisados e nos relatórios de análise crítica de } \\
\text { projetos. } \\
\text { Na análise das fichas de EAV mencionadas, } \\
\text { verificou-se que os estudos realizados abrangiam } \\
\text { propostas para redução de custo em sua maioria e } \\
\text { em alguns casos abrangiam também melhoria do } \\
\text { produto e de aspectos construtivos. } \\
\text { Devido ao fato de que poucos estudos } \\
\text { consideravam uma visão mais abrangente da } \\
\text { cadeia de valor, considera-se que a adesão ao } \\
\text { princípio é apenas parcial. } \\
\text { Em nenhum documento analisado, foi identificado } \\
\text { que esses estudos gerariam conhecimento } \\
\text { reutilizável pela empresa. }\end{array}$ \\
\hline 2 & $\begin{array}{l}\text { Projetista de sistemas } \\
\text { empreendedor } \\
\text { (líder, engenheiro chefe) }\end{array}$ & Nenhuma & $\begin{array}{l}\text { Na análise dos contratos foi identificado que } \\
\text { diferentes agentes tinham e seu escopo a função de } \\
\text { coordenar os projetos. } \\
\text { O fluxo de gestão mostra a divisão de funções em } \\
\text { relação à gestão dos projetos entre Construtora, } \\
\text { Arquitetura e Cliente. } \\
\text { Os dois pontos acima mostram que na gestão do } \\
\text { empreendimento não havia a figura de um líder } \\
\text { único com total responsabilidade e poder de } \\
\text { decisão sobre o Projeto, portanto foi considerado } \\
\text { que neste Empreendimento, não havia nenhuma } \\
\text { adesão à este princípio. }\end{array}$ \\
\hline 3 & $\begin{array}{l}\text { Engenharia simultânea com } \\
\text { múltiplas alternativas }\end{array}$ & Parcial & $\begin{array}{l}\text { Nas atas de reunião analisadas constavam } \\
\text { registros de estudos de alternativas de projeto, } \\
\text { desde a fase de concepção, quando o arquiteto fez } \\
4 \text { opções de projetos, que foram precificadas pela } \\
\text { construtora para que assim o projeto seguisse em } \\
\text { frente. } \\
\text { Nas fichas de EAV analisadas, também existiam } \\
\text { alguns estudos que tratavam de alternativas para } \\
\text { um mesmo sistema, por exemplo, foi realizado um } \\
\text { estudo com } 5 \text { opções de partido de estrutural, no } \\
\text { qual foi comparado o custo e prazo de execução de } \\
\text { cada solução para que a decisão fosse tomada. } \\
\text { No entanto, considera-se que a adesão a esse } \\
\text { princípio é apenas parcial pois esses estudos foram } \\
\text { realizados somente em alguns sistemas e não } \\
\text { sistematicamente como parte do processo de } \\
\text { projeto. }\end{array}$ \\
\hline
\end{tabular}




\begin{tabular}{|c|c|c|c|}
\hline 4 & Cadência, fluxo e puxada & Parcial & $\begin{array}{l}\text { Sobre o planejamento do processo, foi } \\
\text { identificado que desde a reunião de início do } \\
\text { projeto já havia datas marco que deveriam ser } \\
\text { perseguidas ao longo do processo. } \\
\text { Nas atas mostra que ocorrem reuniões mensais de } \\
\text { coordenação para que houvesse troca de } \\
\text { informações e definições com certa frequência ao } \\
\text { longo do processo. } \\
\text { No entanto, foi identificado que apesar de } \\
\text { existirem datas marco que eram de conhecimento } \\
\text { de todos, o processo não estava bem definido e } \\
\text { isso por diversas vezes foi assunto apontado nas } \\
\text { reuniões. De acordo com os registros, não estava } \\
\text { claro a todos os agentes qual o fluxo que deveria } \\
\text { ser seguido para atingir a data meta e assim eles } \\
\text { não estavam sendo capazes de planejar seus } \\
\text { próprios trabalhos para atingi-las. } \\
\text { Além disso, também foram apontadas diversas } \\
\text { indefinições que deveriam ser providas pelo } \\
\text { cliente, que impactavam o fluxo contínuo dos } \\
\text { projetos. }\end{array}$ \\
\hline 5 & $\begin{array}{l}\text { Equipes de especialistas } \\
\text { responsáveis }\end{array}$ & Parcial & $\begin{array}{l}\text { A utilização de equipes de especialistas é uma } \\
\text { prática bastante consolidada em projetos } \\
\text { complexos da Construção Civil. } \\
\text { Conforme mostrado no Quadro 6.1, no } \\
\text { Empreendimento estudado existiam diversos } \\
\text { projetistas e consultores altamente especializados e } \\
\text { capazes de projetar seu próprio trabalho e interagir } \\
\text { entre si para criar as soluções demandadas pelo } \\
\text { Projeto. No entanto, o princípio proposto por Ward } \\
\text { inclui aspectos de geração e registro de } \\
\text { conhecimento, não observados de maneira } \\
\text { sistemática no caso. }\end{array}$ \\
\hline
\end{tabular}

Fonte: Próprio autor (2014).

Em relação ao primeiro principio que trata do foco em valor, no estudo de caso existem registros de estudos que levam a adição de valor ao Produto em consideração, no entanto, claramente o valor não guia o processo de projeto, por isso considera-se que a adesão é apenas parcial.

Quanto à figura da liderança forte, a divisão de funções e do poder de decisão vai contra o princípio enxuto de ter um único agente com essa função no Projeto. Devido a isso, mesmo existindo a figura do coordenador de projetos, considerou-se que este não exerce o papel descrito por Ward et. Al. (2011).

Sobre a utilização de engenharia simultânea, foram identificados no material analisado alguns estudos que seguiam esse conceito, porém estes não foram feitos ao longo de todo processo ou para todos os sistemas.

Quanto ao planejamento do Projeto, a adesão foi parcial pois foi identificado que desde o inicio foram estabelecidas datas meta para as entregas. No entanto, na documentação analisada o processo não pareceu estruturado o suficiente para que este conceito fosse adotado em sua totalidade.

Por fim, o fato de este projeto ser de alta complexidade e do mercado de alto luxo contribuiu para que houvesse um time de especialistas bem estruturado e por isso foi considerada adesão parcial do Empreendimento a este principio. 


\section{CONCLUSÕES}

Baseado no estudo de caso analisado, pode-se concluir que há uma adesão parcial aos princípios enxutos no Empreendimento estudado.

A ausência de uma liderança única com maior autonomia e poder de decisão é um ponto crítico do Empreendimento estudado e baseado nisso, pode ser um ponto de atenção em outros empreendimentos.

O foco em valor e o estudo de alternativas já são aplicados, no entanto, verificou-se que para que seja aplicado em sua totalidade precisa fazer parte do processo de projeto e do sistema de gestão da empresa.

No empreendimento estudado foi identificado que a utilização de datas marco sem o detalhamento de tarefas causa muitas dúvidas caso o processo não esteja bem definido. É possível que se aplicado a outros empreendimentos, o resultado também seja similar, mostrando a necessidade de definir com clareza o processo.

Um ponto de destaque é a utilização de equipes de especialistas, prática que ocorre em empreendimentos de alta complexidade da construção, é o ponto que apresenta maior convergência com os princípios enxutos.

É importante destacar que o Empreendimento estudado é de alto luxo e de grande complexidade técnica e gerencial e, devido a isso, tem uma abordagem diferenciada em relação à forma como é feita a gestão dos seus projetos, o que pode não refletir o mercado de construção brasileiro como um todo mas sim a fatia do mercado a qual ele pertence.

Para trabalhos futuros neste tema, sugere-se a aplicação deste método em outros estudos de caso para que seja possível comparar os resultados. Além disso, um maior detalhamento dos princípios analisados também pode contribuir para a obtenção de resultados mais acurados que poderão servir de base para estudos de aplicação.

\section{REFERÊNCIAS BIBLIOGRÁFICAS}

AGESC. Manual de Escopo de Serviços para Coordenação de Projetos. 2ed. Disponível em: Www.manuaisdeescopo.com.br. 2012. Data de acesso: 06/05/2014 ASSOCIAÇÃO BRASILEIRA DE NORMAS TÉCNICAS. NBR 13531. Elaboração de projetos de edificações - Atividades Técnicas. Rio de Janeiro, 1995.

BALlARD, G., ZABELlE, T. Lean Design: Process, Tools, and Techniques. 15p. White Paper \#10, Lean Construction Institute. EUA, 2000.

DAL FORNO, A.J., FORCELLINI, F.A. Lean Product Development - Principles and Practices. Product: Management \& Development, Vol. $10 n^{\circ}$ 2, Dezembro 2012.

MORGAN, J.M.; LIKER, J.K. Sistema Toyota de Desenvolvimento de Produto: integrando pessoas, processo e tecnologia. Porto Alegre: Bookman, 2008. 392p.

REIFI, M.H.E., EMMITT, S. Perceptions of lean design management. Architectural Engineering and Design Management, 2013

WARD, A.C. Sistema Lean de Desenvolvimento de Produtos e Processos. 1 ed. São Paulo: Leopardo Editora , 2011.209 p.

WOMACK, J.P.; JONES, D.T.; ROOS, D. A máquina que mudou o mundo. 8.ed. Rio de Janeiro: Elsevier, 2004. 332p. 